\title{
Tumores pardos en múltiples localizaciones: manifestación de osteodistrofia renal severa. Caso Clínico
}

\author{
María Cecilia Gómez $\mathbf{S c h}^{1}$, Patricia Riquelme $\mathbf{S}^{2}$, \\ Gianina Sirandoni $\mathbf{R}^{3}$, Jorge Sapunar $\mathbf{Z}^{4}$, \\ Esteban Princic $\mathbf{H}^{5}$, Bolívar Lee $\mathbf{0}^{6}$. \\ Brown tumors in multiple locations \\ as a manifestation of severe renal \\ osteodystrophy. Report of one case
}

\begin{abstract}
We report a 25 years old woman with a four years history of end stage renal disease on hemodialysis. During the last two years of follow up, multiple tender nodules appeared in the left clavicle and ribs. These were diagnosed as brown tumors, secondary to osteitis fibrosa cystica, in the context of a secondary hyperparathyroidism. A subtotal parathyroidectomy was performed and a homologous parathyroid implant was done in the right forearm. The pathological study of the surgical pieces confirmed the presence of the brown tumors and parathyroid hyperplasia. Nine months after surgery, parathormone levels and brown tumor calcifications decreased significantly and bone mineral density increased by $20 \%$. (Rev Méd Chile 2003; 131: 1183-87) .
\end{abstract}

(Key Words: Brown tumors; Osteritis fibrosa cystica; Parathyroid neoplasms)

Recibido el 11 de diciembre, 2002. Aceptado en versión corregida el 17 de julio, 2003. ${ }^{1}$ Unidad de Nefrología, ${ }^{2}$ Servicio de Medicina Interna, ${ }^{3}$ Servicio Medicina Nuclear, ${ }^{4}$ Unidad de Endocrinología, ${ }^{5}$ Servicio de Radiología, ${ }^{6}$ Servicio de Anatomía Patológica. Hospital Regional Temuco.

$\mathrm{E}^{1}$ hiperparatiroidismo secundario es una complicación frecuente de la insuficiencia renal crónica (IRCr), siendo su expresión esquelética la osteítis fibrosa quística (OFQ).

Los tumores pardos (TP) son una variante de osteítis fibrosa quística, raramente reportados en pacientes con IRCr, con una incidencia que va de 1,5 a $1,7 \%{ }^{1}$.

Son lesiones óseas benignas, expresión de un remodelado óseo acelerado, secundario a niveles persistentemente elevados de hormona paratioidea (PTH), que determinan un incremento en la actividad osteoclástica y fibrosis peritrabecular progresiva ${ }^{2,3}$.

Correspondencia a: Dra. María Cecilia Gómez Schilling. Andrés Bello 168. Temuco IX Región-Chile. Fono: 45238346, Fax: 45-272257.
La presencia de tumores pardos múltiples se asocia habitualmente con carcinoma de paratiroides e hiperparatiroidismo primario ${ }^{4}$.

Nuestro propósito al comunicar este caso clínico, es destacar que los TP múltiples también pueden observarse en osteítis fibroquística por hiperparatiroidismo secundario (HPT $2^{\circ}$ ) en IRCr.

Caso Clínico: Mujer de 25 años con antecedentes de glomerulopatía primaria, debido a síndrome nefrótico a los 14 años, diagnosticado clínicamente por cuadro edematoso con ascitis, en el laboratorio presentó proteinuria de 7,3 g en $24 \mathrm{~h}$, hipoproteinemia: 5,3 g\%, hipoalbuminemia: 2,2 g\%, C3 bajo, ecotomografía renal mostró riñones de $11,5 \mathrm{~cm}$, simétricos, con difusa acentuación de 
la ecogenicidad cortical. No fue posible realizar biopsia renal por no contar con la autorización de la familia.

La paciente se perdió de sus controles y tratamiento durante 8 años, hasta agosto de 1998 cuando ingresó al Servicio de Urgencia del Hospital Regional de Temuco, a los 22 años por un síndrome urémico y anemia severa. Los exámenes demostraron: uremia $345 \mathrm{mg} / \mathrm{dl}$, creatinina $15 \mathrm{mg} /$ $\mathrm{dl}$, hematocrito $14 \%$, ecotomografía abdominal con riñones disminuidos de tamaño, por lo que ingresó al programa de hemodiálisis crónica.

La paciente mantuvo niveles de calcemia ligeramente baja (7,5-8,5 $\mathrm{mg}$ ) y fosfemia en rangos normales a levemente aumentados (3,4-5,8 $\mathrm{mg}$ ) recibió terapia con carbonato de calcio oral a dosis altas.

En los últimos 2 años, refirió dolores óseos difusos de leve a moderada intensidad, con un aumento progresivo de volumen nodular a nivel de clavícula izquierda, $7^{\circ}, 8^{\circ}, 9^{\circ}$ costillas bilaterales y tobillo derecho, por lo que se indicó hospitalización para estudio en agosto de 2001.

Examen Físico: Masas de consistencia dura, dolorosas a la palpación profunda, en $1 / 3$ proximal de clavícula izquierda, $7 \stackrel{a}{a} 8^{\underline{a}}$ y $9^{a}$ costillas y $1 / 3$ distal de peroné derecho.

Exámenes de laboratorio - agosto 2001: Calcemia: $8,2 \mathrm{mg}$, fosfemia: $4,4 \mathrm{mg}$; fosfatasas alcalinas: 7,929 U/L; PTH: 1,405 pcg/ml, hematocrito 22\%.

Exámenes de Imágenes:

Radiografías: Calota: Imágenes en sal y pimienta. Huesos largos: múltiples imágenes quísticas en 1/3 proximal de clavículas, húmero, parrilla costal, fémur izquierdo, tibia y peroné derecho (Figura 1a), 1/3 medio de peroné izquierdo, cuello femoral izquierdo y pelvis.

Tomografía Axial Computarizada (TAC): Tórax: Múltiples imágenes óseas de aspecto tumoral, en arcos costales, clavículas y cuerpos vertebrales. (Figura 2a).

Ecografía: Cuello: Imágenes infratiroideas nodulares, derecha: $7 \mathrm{x} 5 \mathrm{~mm}$, izquierda: $5 \times 3 \mathrm{~mm}$. Sugerentes de adenomas o hiperplasia de paratiroides.
Cintigrama: 1. Oseo: Múltiples focos de actividad osteoblástica, descritos en las radiografías. 2. Paratiroides (Sestamibi-Tc 99): Tejido paratiroideo anormal derecho e izquierdo.

Densitometría Osea: Osteoporosis de cuellos femorales y osteopenia de cuerpos vertebrales.

\section{Manejo y Seguimiento}

Considerando la severidad del HPT $2^{\circ}$ se decidió tratamiento quirúrgico. El 23 de agosto de 2001, fue sometida a paratiroidectomía subtotal, con 1/2 glándula in situ e implante de 1 glándula en el antebrazo derecho, decisión del grupo quirúrgico para prevenir hipoparatiroidismo si fracasaba el implante. Además se tomó una biopsia de la masa nodular de la clavícula izquierda.

El estudio histopatológico demostró: (Figura 3) Hiperplasia paratiroidea, Tumor pardo.

En el postoperatorio inmediato se manejó con monitorización de calcemias y fosfemias, administración de gluconato de calcio, alfacalcidol i.v. y carbonato de calcio oral para prevenir una hipocalcemia severa.

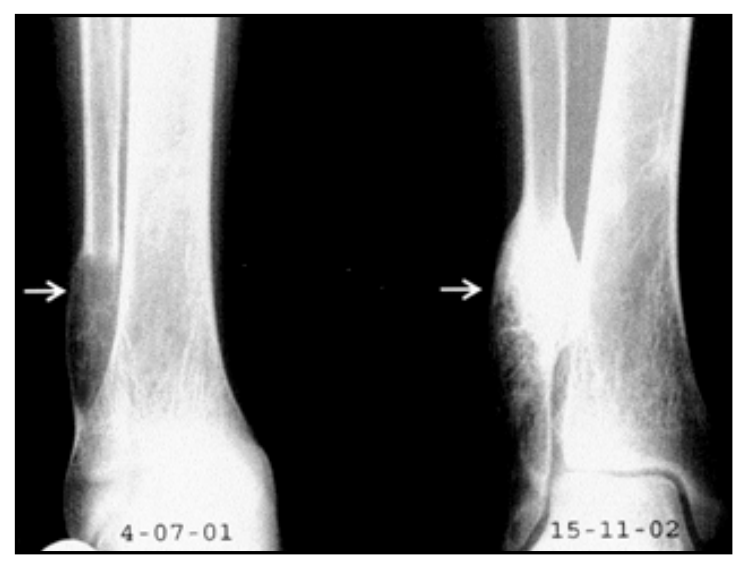

FiguRA 1. 1a: Radiografía de peroné derecho: Se observa imagen de masa radiolúcida que sustituye al hueso en su tercio distal correspondiente a Tumor Pardo. 1b: La misma imagen después de 9 meses de la cirugía, donde se observa la calcificación casi total de la masa que se observaba previamente. 
Posteriormente se ha mantenido en tratamiento con alfacalcidol oral postdiálisis y carbonato de calcio oral de manera permanente, con control mensual de calcemia y fosfemia, fosfatasas alcalinas y PTH cada 3 meses.

A los 9 meses de la cirugía (abril 2002) la paciente había evolucionado clínicamente en forma satisfactoria con desaparición de los dolores óseos y disminución de las masas óseas. En ese momento se evaluaron comparativamente los parámetros del estudio, encontrando que los niveles de PTHi descendieron de $1.405 \mathrm{pcg} / \mathrm{ml} \mathrm{a} 63 \mathrm{pcg} /$ $\mathrm{ml}$, las fosfatasas alcalinas de 7,929 U/L a $392 \mathrm{U} / \mathrm{L}$, calcemia: $9,2 \mathrm{mg} \%$, fosfemia $4,1 \mathrm{mg} \%$.

El estudio radiológico mostró un discreto aumento de la densidad ósea. (Figura 1).

En la TAC de tórax se observó calcificación de los TP en costillas y vértebras (Figura 3).

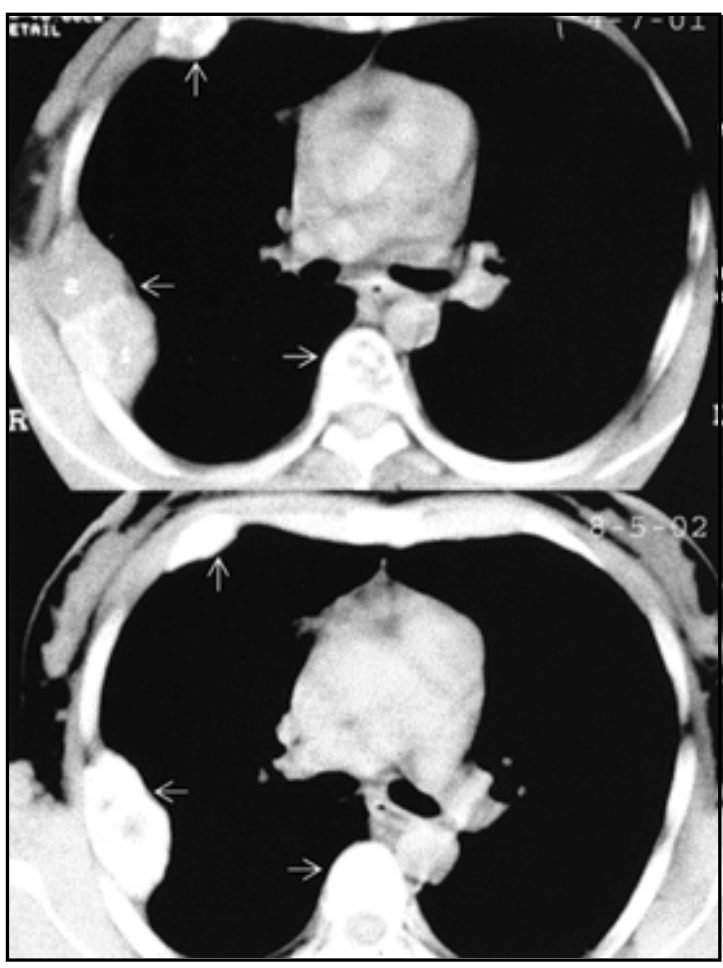

FIGURA 2. 2a: Tomografía axial computarizada de tórax: Con múltiples imágenes de tumores pardos a nivel de costillas y uno en vértebra. $2 \mathrm{~b}$ : Control a los 9 meses, al mismo nivel, observando disminución y calcificación casi total de los tumores pardos de costillas y desaparición del que se encontraba a nivel vertebral.

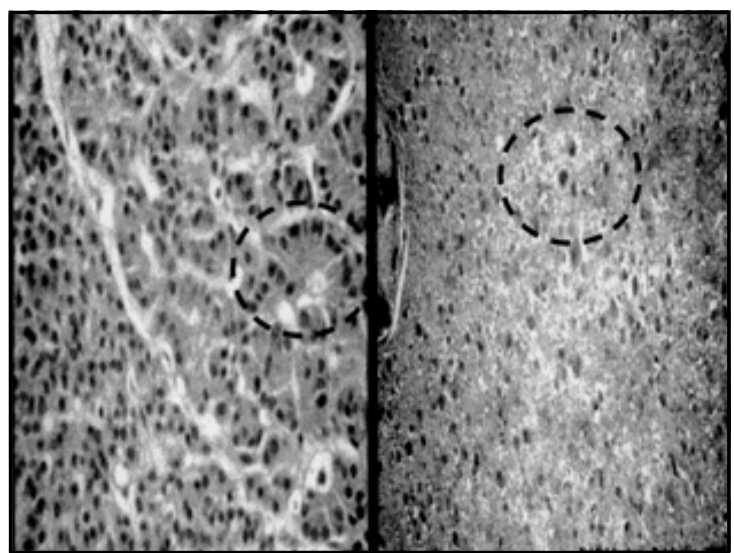

Figura 3. 3a: Histología de corte de paratiroides: Donde se observa gran hiperplasia celular. 3b: Histología de corte de Tumor Pardo de clavícula derecha: Destacan células gigantes multinucleadas, en un fondo de estroma rico en fibroblastos, y acúmulo de hemosiderina que le confiere el color pardo.

La densitometría ósea mostró $20 \%$ de remineralización, pasando del rango de osteopenia a mineralización normal a nivel vertebral y de osteoporosis a osteopenia a nivel de cuellos femorales, disminuyendo significativamente el riesgo de fracturas.

\section{DisCUSIÓN}

Los TP son la expresión de una OFQ severa, clasificados como lesiones de alto remodelado e histológicamente benignas ${ }^{5,6}$.

En 1963, Fordcham ${ }^{7}$ describió por primera vez la asociación de un tumor pardo e hiperparatimidismo $2^{\circ}$ en IRCr. Los TP histológicamente están formados por microhemorragias, macrófagos y células gigantes multinucleadas del tipo osteoclástico en un estroma fibrovascular, siendo prominentes los depósitos de hemosiderina que le confieren el color pardo ${ }^{8}$.

En pacientes con IRCr, la incidencia de TP es de 1,5 a 1,7\%1, las localizaciones más frecuentes están en las costillas, clavícula, pelvis y mandíbula ${ }^{1,9,15}$ más raramente son reportados en vértebras y órbita ${ }^{10}$.

La edad de presentación es entre los 7 y 70 años, más frecuentes en la segunda década de la vida. Clínicamente se presentan como masas palpables y dolorosas. 
Los cambios bioquímicos incluyen niveles de calcio sérico disminuido o en rango normal bajo; fósforo sérico elevado, fosfatasas alcalinas aumentadas y PTH elevada 6 .

En las radiografías simples se observa una lesión expansiva bien delimitada y áreas radiolúcidas de resorción ósea, reacción subperióstica y ausencia de lámina dura. En la tomografía computarizada se observan calcificaciones así como un proceso óseo expansivo ${ }^{1}$. En el cintigrama de paratiroides con Sestamibi Tc99, pueden ser identificadas las glándulas paratiroides hiperplásicas ${ }^{11}$.

El diagnóstico diferencial incluye al granuloma reparativo de células gigantes, el tumor de células gigantes, la displasia fibrosa y el quiste óseo aneurismático ${ }^{12,13}$. Histológicamente las células gigantes del TP son más pequeñas y poseen una distribución en grupos de características benignas, son de tipo osteoclástico, las del tumor de células gigantes son pseudo-osteoclásticas y muy grandes, en el granuloma reparativo de células gigantes y el quiste aneurismático éstas son osteoclásticas y resortivas. Los antecedentes y los exámenes bioquímicos, en especial la hormona paratiroidea establecen el diagnóstico diferencial $^{14,19}$. La presencia de múltiples TP, pueden simular enfermedad ósea metastásica ${ }^{15}$.

El manejo de los TP depende de la severidad de las lesiones óseas, dirigido a corregir el hiperparatiroidismo $2^{\underline{0}}$, mediante la normalización de los niveles de calcio, fósforo y PTH, con vitamina $\mathrm{D}$ activa i.v. u oral, suplementos de calcio oral, quelantes de fósforo y régimen hipofosfémico.

En casos muy severos o refractarios al tratamiento médico, es necesaria la cirugía, pudiendo realizarse una paratiroidectomía subtotal o total.

\section{REFERENCIAS}

1. Brown T, Genant H, Hattner R, Sheldon O, Potter D. Multiple Brown Tumors in a patient with chronic renal failure and secondary hiperparathyroidism. Am J Roentgenol 1977; 128: 131-4.

2. Wyngaarden JB, Smith LH, Cecil RL. Cecil Textbook of Medicine 19 Philadelphia; WB Saunders, 1992.

3. Fineman I, Johnson JP, Di-Patre, Sandhu H. Chronic renal failure causing brown tumors and myelopatty. J Neurosurgery 1999; 90 (4 suppl): 242-6.
En el caso de nuestra paciente el largo tiempo de enfermedad, aproximadamente 11 años, motivó un estímulo permanente a nivel de producción de PTH en las paratiroides, provocando una desmineralización ósea generalizada, con la presencia de múltiples tumores pardos a todo nivel.

Casos tan severos son raros de encontrar actualmente, ya que los pacientes son diagnosticados de manera precoz.

El estudio diagnóstico demostró la severidad de la enfermedad, catalogada como un HPT $2^{-}$ grave, por sus niveles de PTHi mayores a 1.000 $\mathrm{pcg} / \mathrm{ml}$, el grado de osteoporosis y osteopenia a nivel de cuellos femorales y vértebras. La conducta fue quirúrgica, mediante paratiroidectomía subtotal con implante en antebrazo.

Nuestra paciente requirió altas dosis de calcio oral y alfacalcidol durante los primeros 3 meses postoperatorios, dosis que fueron disminuyendo a medida que se normalizaba la PTHi.

Realizamos un control completo para objetivar la mejoría de los parámetros bioquímicos y los cambios a nivel radiológico, de la TAC y la mineralización mediante la densitometría.

$\mathrm{Al}$ suprimir efectivamente la PTH con la cirugía, se produjo calcificación y regresión de los TP de manera importante, llegando incluso algunos a no observarse y en la densitometría se observó una mejoría de $20 \%$.

Podemos concluir que los TP en la IRCr, son una manifestación de un HPT $2^{\circ}$ grave no controlado y que al manejar efectivamente éste, se produce una regresión de los tumores y recuperación paulatina del estado de mineralización ósea.

4. Pai M, Park CH, Kim BS, Chung YS, Park HB. Multiple Brown Tumors in parathyroid carcinoma mimicking metastatic bone disease. Clin Nucl Med 1997; 22: 691-4.

5. Sutton and Cameron. Renal Osteodystrophy. Pathophysiology Seminars in Nephrology 1992; 12: 91-100.

6. Orejas G, Corsino R, Vicente SG, Fernandez L, Santos F, Malaga S. Maxillary brown tumor as manifestation of renal osteodystrophy. Nephron 1993; 64: 483-4. 
7. Fordham CC, Wiwams TF. Brown tumor and secondary hyperparathyroidism. N Engl J Med 1993; 269: 129-31.

8. Keysen J, Postman G. Brown tumor of the mandibule. Am J Otolaryngol 1996; 17: 407-10.

9. Cuo P, Solomon M. Brown tumor associated with secondary hyperparathyroidism of chronic renal failure. J Laryngol Oto 1997; 85; 737-42.

10. PARRISH C, O'DAY D. Brown tumor of the orbit. Arch Ophthalmol 1986; 104: 1199-202.
11. MUthiah A JR, Kalain JB, KatZ DS. Uptake Tc 99m Sestamibi by brown tumor in a patient with primary hiperparathyroidism. Clin Nucl Med 1998; 23: 83-5.

12. Levine M, Chu A, Abdul-Karim F. Brown tumor and secondary hiperparathyrodism. Arch Ophthalmol 1991; 109: 847-9.

13. GoRETH G, AMEDEE R. Giant cell reparative granuloma presenting as a midline nasal mass. ENT 1991; 70:1.

14. Som P, Lawson W, Cohen B. Giant-cell lesions of the facial bones. Radiology 1983; 147: 129-34. 